\title{
Systematic review and meta-analysis: the effect of bronchopulmonary dysplasia on neurodevelopment in very low birth weight premature infants
}

\author{
Shuqiang Gao, Xiaolong Zhang, Weina Du, Xiaofeng Zhou, Yufeng Xi, Rong Ju \\ Department of Neonatology, Chengdu Women's and Children's Central Hospital, School of Medicine, University of Electronic Science and \\ Technology of China, Chengdu, China \\ Contributions: (I) Conception and design: S Gao, R Ju; (II) Administrative support: X Zhang; (III) Provision of study materials or patients: S Gao, X \\ Zhang, W Du, X Zhou, Y Xi; (IV) Collection and assembly of data: All authors; (V) Data analysis and interpretation: W Du, X Zhou, Y Xi, R Ju; (VI) \\ Manuscript writing: All authors; (VII) Final approval of manuscript: All authors. \\ Correspondence to: Rong Ju. No. 1617, Riyue Avenue, Qingyang District, Chengdu, China. Email: jurong123@126.com.
}

Background: A meta-analysis was performed to study the effect of steroid intervention on the neurodevelopment of extremely low birth weight preterm infants complicated with bronchopulmonary dysplasia, and to provide a theoretical basis for clinical treatment.

Methods: The Wanfang database, Chinese Biomedical Literature database, VIP database, Baidu Academic, CNKI database, The Cochrane Library, Medline, Embase, and PubMed database were searched by computer from establishment to 2021. Randomized controlled trials on the effect of steroids on neurodevelopment in very low birth weight preterm infants with bronchial dysplasia published from January 10, 2007 were retrieved. The included literature was evaluated for bias risk, then analyzed using RevMan 5.3 software.

Results: A total of 9 studies were included, with a total of 2,453 patients. The funnel plot showed that the circles and the midline of some studies were basically symmetrical, and there was no bias in the publications. The conclusions obtained were relatively reliable. Cerebral palsy, neurodevelopmental indicators, and MRI findings of preterm infants were analyzed. The cognitive impairment of very low birth weight preterm infants complicated with bronchial dysplasia ( $R R=0.83$, 95\% CI: $0.72-0.96, P=0.01$ ) in the treatment group was significantly different from that in the control group, while cerebral palsy ( $R R=0.99,95 \%$ CI: 0.75-1.29, $\mathrm{P}=0.93$ ), speech impairment $(\mathrm{RR}=0.75,95 \% \mathrm{CI}: 0.46-1.21, \mathrm{P}=0.24)$, hearing loss requiring amplification ( $R R=0.60,95 \%$ CI: $0.35-1.03, P=0.06$ ), bilateral blindness $R R=0.81,95 \%$ CI: $0.52-1.24, P=0.32$ ), severe intraventricular hemorrhage $(\mathrm{IVH})(\mathrm{RR}=0.71,95 \% \mathrm{CI}: 0.33-1.50, \mathrm{P}=0.37)$, and cystic periventricular leukomalacia ( $\mathrm{RR}=0.82,95 \% \mathrm{CI}: 0.43-1.57, \mathrm{P}=0.56)$ had no significant differences compared with the control group.

Discussion: In this meta-analysis, we found that the use of steroids in very low birth weight preterm infants complicated with bronchial dysplasia had significant effects on cognition, but no significant effects on hearing, vision, or language function.

Keywords: Very low birth weight; premature infants; bronchopulmonary dysplasia; steroids; neurodevelopment

Submitted Aug 31, 2021. Accepted for publication Oct 29, 2021.

doi: $10.21037 /$ tp-21-449

View this article at: https://dx.doi.org/10.21037/tp-21-449 


\section{Introduction}

Due to the improvements at the medical level and nursing level, there are more and more very low birth weight premature babies being delivered (1). After they are born, they need to be carefully nursed, and the nursing process will incur huge costs, which often renders originally poor families worse off $(2,3)$. In addition, various complications may occur to varying degrees during nursing, such as infection, necrosis of the small intestine and colon, bronchopulmonary dysplasia, In addition, they will suffer various complications to varying degrees during care, such as infection, small intestine and colon necrosis, and bronchopulmonary dysplasia, of which bronchopulmonary dysplasia is the main cause affecting the late life quality of premature infants, among which bronchopulmonary dysplasia is the main cause affecting the quality of life of premature infants in the later period (4).

There are many reasons for the occurrence of bronchopulmonary dysplasia, and the common reasons are high oxygen content lack of the ability to remove free radicals, and lack of vitamin $\mathrm{A}$ and vitamin $\mathrm{E}$, which will cause lung injury in premature infants or abnormal repair after lung injury $(5,6)$. In addition, premature rupture of membranes and small gestational age contribute to the occurrence of bronchial dysplasia, and are some of the common symptoms of extremely low birth weight preterm infants (7). Studies have shown that it is easier to induce bronchial hypoplasia in premature infants in a hyperoxic environment and cause damage to alveolar cells (8). Studies have also pointed out that preterm infants with bronchial dysplasia will suffer from recurrent respiratory tract infections and pulmonary arterial hypertension, leading to increased mortality (9). Therefore, the treatment of neonatal bronchopulmonary dysplasia is crucial. Clinical trials have confirmed that steroids can reduce the incidence of bronchial dysplasia in low birth weight premature infants, but steroids applied to extremely low birth weight preterm infants through systemic therapy is quite controversial. This is because at the same time as reducing the incidence of bronchial dysplasia, infants are likely to have poor resistance to premature nervous system damage $(10,11)$.

At present, $6-30 \%$ of preterm infants are still treated with steroids for the prevention and treatment of bronchial dysplasia in clinical trials (12). In previous studies, lowdose treatment with certain steroids resulted in significant adverse effects on neurodevelopment. Steroids and other substances have been used in the treatment of bronchial dysplasia, however, most of the literature involve small sample sizes and are single-center studies, and the effect on the nervous system has not yet been determined $(13,14)$. This systematic review and meta-analysis collected the randomized controlled trials on low birth weight infants complicated with bronchial dysplasia in order to assess the impact of steroid treatment on their neurodevelopment. It is hoped that this comprehensive analysis will provide a theoretical basis for treatment and further guide the clinical treatment of premature infants complicated with bronchopulmonary dysplasia.

We present the following article in accordance with the PRISMA reporting checklist (available at https://dx.doi. org/10.21037/tp-21-449).

\section{Methods}

\section{Literature retrieval}

The Wanfang database, Chinese Biomedical Literature database, VIP database, Baidu Academic, CNKI database, The Cochrane Library, Medline, Embase, and PubMed database were searched by computer. Randomized controlled trials on the effect of steroids on neurodevelopment in very low birth weight preterm infants complicated with bronchial dysplasia were retrieved from the database establishment until January 10, 2021, and related articles were retrieved by combining search terms. Chinese search terms included "dexamethasone", "hydrocortisone", "budesonide", "premature baby", "bronchial dysplasia", and "neurodevelopment". Reference terms included "dexamethasone", "hydrocortisone", "budesonide", "threatened babies", "bronchopuldysplasia", and "neurodevelopment". The quality of the literature was then evaluated using the Cochrane Systematic Reviews Manual.

The above-mentioned search words are freely combined, and the identified documents are searched for many times, and then the identified documents are traced by the search engine. And get the latest research progress after contacting experts and researchers in the field.

\section{Inclusion and exclusion criteria for articles}

Inclusion criteria: (I) subjects were preterm infants with gestation less than 28 weeks and birth weight less than $1 \mathrm{~kg}$; (II) for clinical control analysis, the same amount of placebo was used in the treatment of very low birth weight preterm infants complicated with bronchopulmonary dysplasia; (III) 
for similar studies conducted by the same team, articles with high relevance or the largest research project were selected; (IV) randomized controlled trials with literature in English and Chinese, and no national restrictions; (V) the research project included the occurrence of cerebral palsy, related indicators of neurodevelopmental disorders, and MRI status.

Exclusion criteria: (I) duplicate articles; (II) the treatment measures were not related to the title of the article; (III) unable to view the full text of the article; (IV) reviews and non-clinical research articles; (V) articles that were not randomized controlled trials; (VI) the results did not include relevant indicators.

The titles, abstracts, and full texts of the selected articles were read and screened by two researchers. Before screening, three pre-experiments were performed. When there was disagreement between researchers, the two researchers reached a consensus through discussion.

\section{Observation indexes}

The observation indexes included cerebral palsy, neurodevelopmental disorder-related indicators such as hearing loss requiring amplification, bilateral blindness, cognitive impairment, and language impairment, and magnetic resonance imaging indicators including cystic periventricular leukomalacia and severe intraventricular hemorrhage (IVH).

\section{Data extraction}

Two experts used a unified Microsoft Excel spreadsheet to independently extract data. Before data extraction, three pre-experiments were performed. When there was a disagreement between researchers, the two experts reached a consensus through discussion. The basic features of the included literature were extracted: (I) the name of the first author; (II) year of publication; (III) sample size; (IV) research design types; (V) the use of drugs; (VI) observation indicators including the condition of cerebral palsy, neurodevelopmental disorder-related indicators, and magnetic resonance imaging.

\section{Risk of bias and quality assessment}

The Cochrane system evaluator's guide (with RevMan 5.3 software) was used to evaluate the risk of bias in randomized trials. The specific items of quality assessment included: (I) whether the random allocation method was correct; (II) whether the allocation scheme was hidden; (III) whether the method was correct; (IV) whether the blind method was used correctly for the study subjects, treatment plan, and experimental results; (V) selective reporting of research results; (VI) whether the research data was complete. The above 6 items were judged as "high risk bias", "low risk bias", and "unclear".

\section{Statistical processing}

The risk of bias of the included studies was assessed using the bias risk assessment diagram of RevMan 5.3 software. Each effect was expressed using a $95 \%$ confidence interval (CI). When $\mathrm{P}>0.01$ and $\mathrm{I}^{2}<50 \%$, a fixed effects model was used for meta-analysis. When $\mathrm{P}<0.01$ and $\mathrm{I}^{2}>50 \%$, a random effects model was used for meta-analysis.

\section{Results}

\section{Literature search results}

Figure 1 shows the flowchart of literature retrieval and screening. A total of 563 publications were retrieved, including 245 publications in Chinese and 318 in English. According to the titles and abstracts of the articles, 466 articles were excluded, and 88 articles were excluded after reading the full texts. Finally, nine articles were included in the meta-analysis. The main reasons for exclusion were: repeated articles (227 articles); therapeutic measures were not related to the title of the paper (117 articles); reviews and non-clinical studies (30 articles); articles that were not randomized controlled trials ( 26 articles); the full text could not be viewed (134 articles); the results did not include relevant indicators (20 articles).

Ten articles met the inclusion criteria, with a total sample size of 3,128 cases. All studies were randomized controlled trials. Among them, five studies were small sample studies with sample sizes ranging from 57 to 252 cases. The ten articles described in detail the sample size, experimental methods, drug use, cerebral palsy, neurodevelopment, and MRI findings. Table 1 shows the basic characteristics of the included literature.

\section{Evaluation results of the risk of bias of the included literature}

Figures 2,3 show the evaluation results of multiple risk of bias aspects of the included studies drawn by RevMan 


\section{Identification of studies via databases and registers}
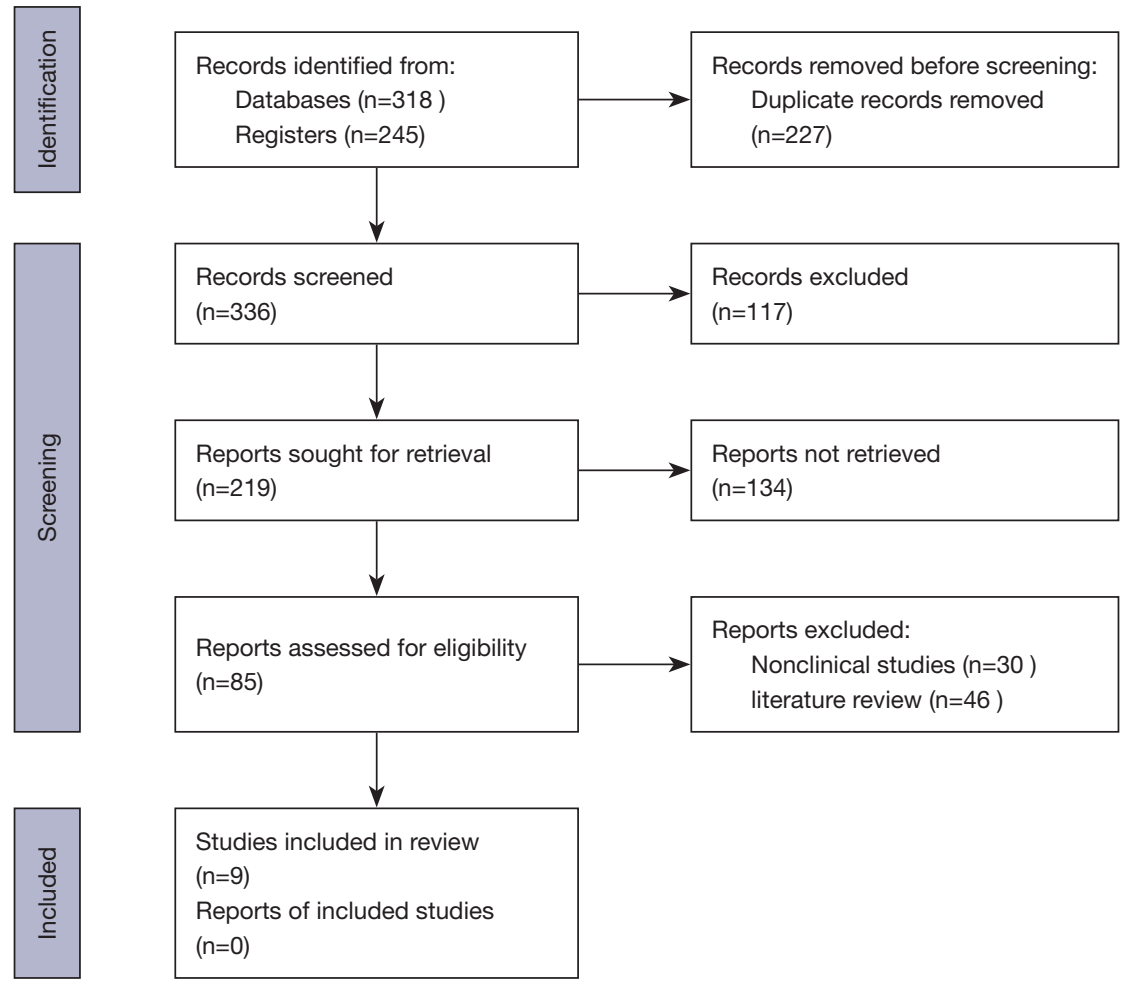

Figure 1 Document retrieval and screening flowchart.

Table 1 Basic characteristics of the included literature

\begin{tabular}{|c|c|c|c|c|}
\hline First author & $\begin{array}{l}\text { Published } \\
\text { year }\end{array}$ & $\begin{array}{c}\text { Sample size } \\
\text { (example), treatment } \\
\text { group/control group }\end{array}$ & $\begin{array}{l}\text { Drug, treatment group/ } \\
\text { control group }\end{array}$ & Indicators \\
\hline Baud O & 2017 & $256 / 267$ & Hydrocortisone/placebo & $\begin{array}{l}\text { The condition of cerebral palsy, hearing loss requiring } \\
\text { amplification, bilateral blindness, language impairment }\end{array}$ \\
\hline Bassler D & 2018 & $308 / 321$ & Dexamethasone/placebo & $\begin{array}{l}\text { The condition of cerebral palsy, hearing loss requiring } \\
\text { amplification, bilateral blindness, cognitive impairment }\end{array}$ \\
\hline Watterberg KL & 2007 & $126 / 126$ & Hydrocortisone/placebo & The condition of cerebral palsy \\
\hline Hitzert MM & 2014 & $17 / 17$ & Dexamethasone/placebo & $\begin{array}{l}\text { Cystic periventricular leukomalacia, severe } \\
\text { intraventricular hemorrhage }\end{array}$ \\
\hline Rastogi A & 1996 & $36 / 34$ & Dexamethasone/placebo & $\begin{array}{l}\text { Cystic periventricular leukomalacia, severe } \\
\text { intraventricular hemorrhage }\end{array}$ \\
\hline
\end{tabular}




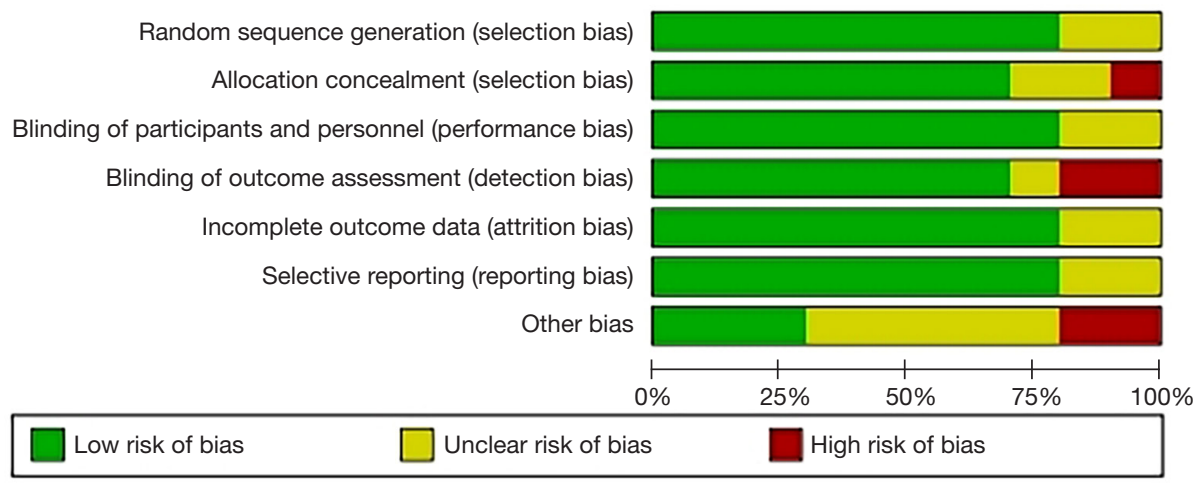

Figure 2 Evaluation results of the literature risk of bias assessment.
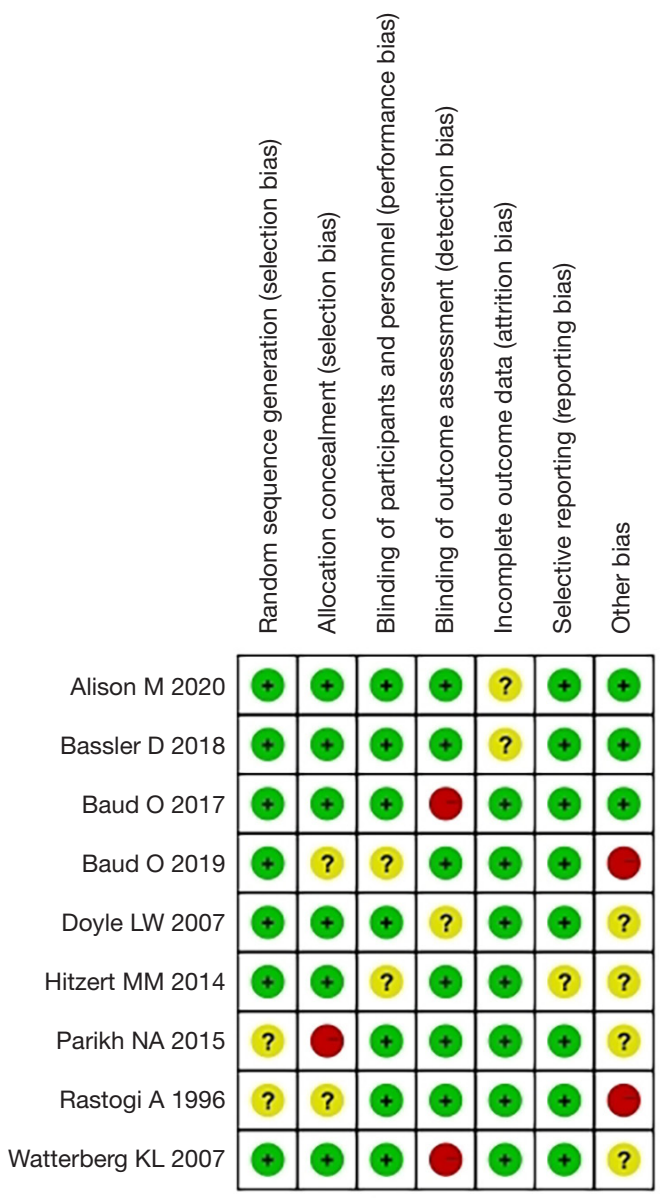

Figure 3 Multiple studies corresponded to multiple risk bias evaluation results.
5.3 software. In this study, among the 9 randomized controlled trials, seven studies $(2-7,10)$ described the correct random allocation method, one (1) did not use allocation concealment, two $(3,5)$ did not use the double-blind method, and the blind method was not used in the rest of the studies. The data of seven studies $(1-3,5,6,8,9)$ were complete. Therefore, the measurement bias was small, the reporting bias was small, while the overall quality of the included literature and the strength of evidence were relatively high.

\section{Meta-analysis of cerebral palsy}

Figure 4 shows the forest plot for the meta-analysis results of cerebral palsy in the two groups of premature infants. The figure shows that of the nine articles, six articles reported on patients with cerebral palsy, including a total of 2,054 patients. The treatment group included 1,009 very low birth weight premature babies, and the control group included 1,045 very low birth weight premature babies. Heterogeneity analysis was carried out on cerebral palsy, and the heterogeneity among literature was low $(\mathrm{P}=0.81$, $\left.\mathrm{I}^{2}=0 \%<50 \%\right)$. The meta-analysis results showed that there was no significant difference in cerebral palsy between the treatment group and the control group $(\mathrm{RR}=0.99,95 \% \mathrm{CI}$ : $0.75-1.29, \mathrm{P}=0.93)$.

\section{Meta-analysis of cognitive impairment}

Figure 5 shows the forest plot of the meta-analysis results 


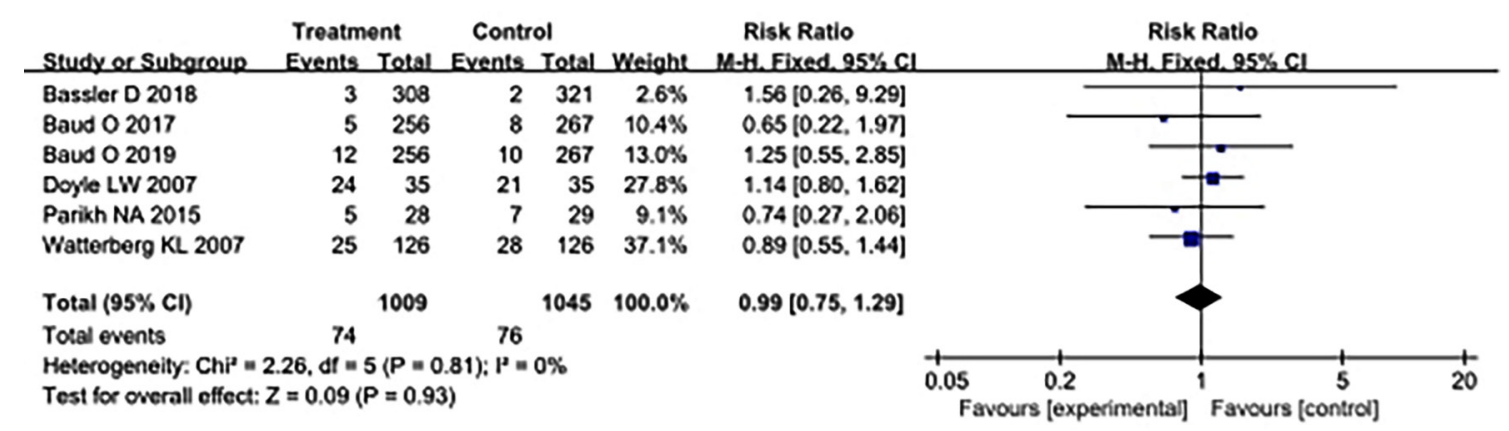

Figure 4 Cerebral palsy of patients in the two groups.

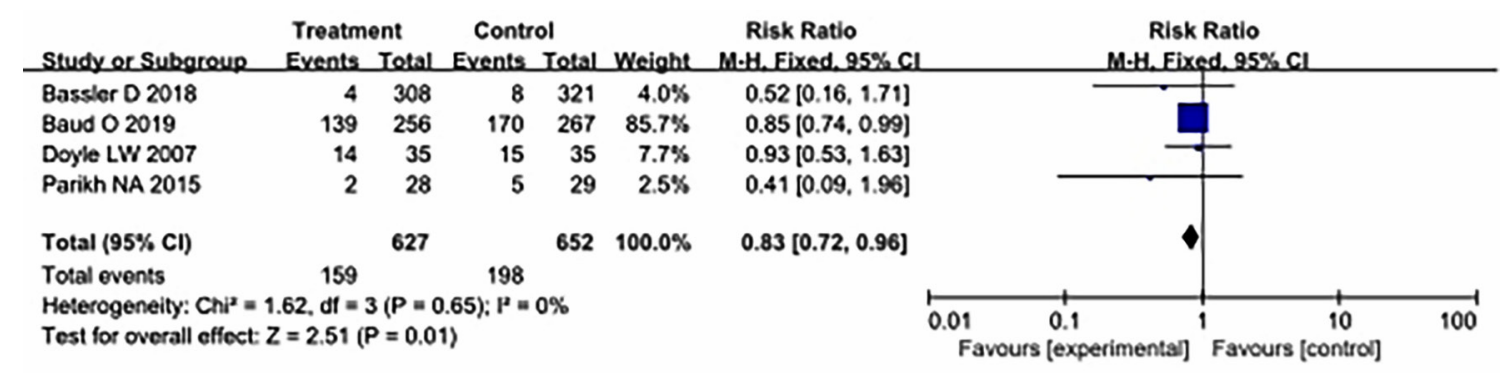

Figure 5 Cognitive impairment in the two groups.

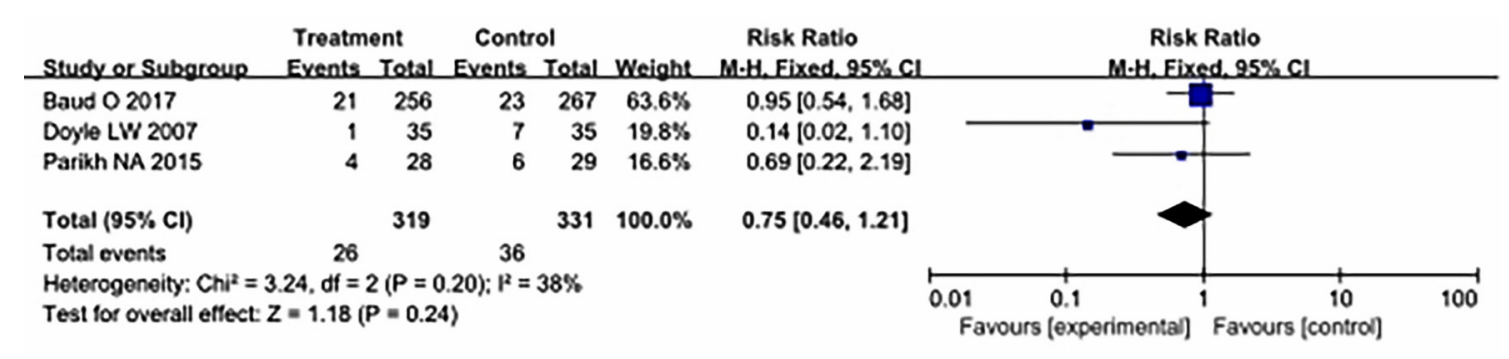

Figure 6 Language disorders in the two groups.

of cognitive impairment in the two groups. The figure shows that of the nine articles, there were four articles which reported on patients with cognitive impairment, including a total of 1,279 very low birth weight premature babies. The treatment group included 627 patients and the control group included 652 patients. The heterogeneity of cognitive impairment was analyzed, and the heterogeneity among literature was low $\left(\mathrm{P}=0.65, \mathrm{I}^{2}=0 \%<50 \%\right)$. The meta-analysis results showed that the cognitive impairment of patients in the treatment group was significantly different from that in the control group ( $R R=0.83,95 \%$ CI: $0.72-0.96, \mathrm{P}=0.01$ ).

\section{Meta-analysis of language disorders}

Figure 6 shows the forest plot of the meta-analysis results of language disorders in the two groups. The figure shows that of the nine articles, there were three articles which reported on patients with language disorders, including a total of 650 very low birth weight premature babies. The treatment group included 319 patients and the control group included 331 patients. Heterogeneity analysis was conducted for language disorders, and the heterogeneity among literature was low $\left(\mathrm{P}=0.20, \mathrm{I}^{2}=38 \%<50 \%\right)$. The meta-analysis results showed that there was no significant difference in language disorders between the treatment group and the control 


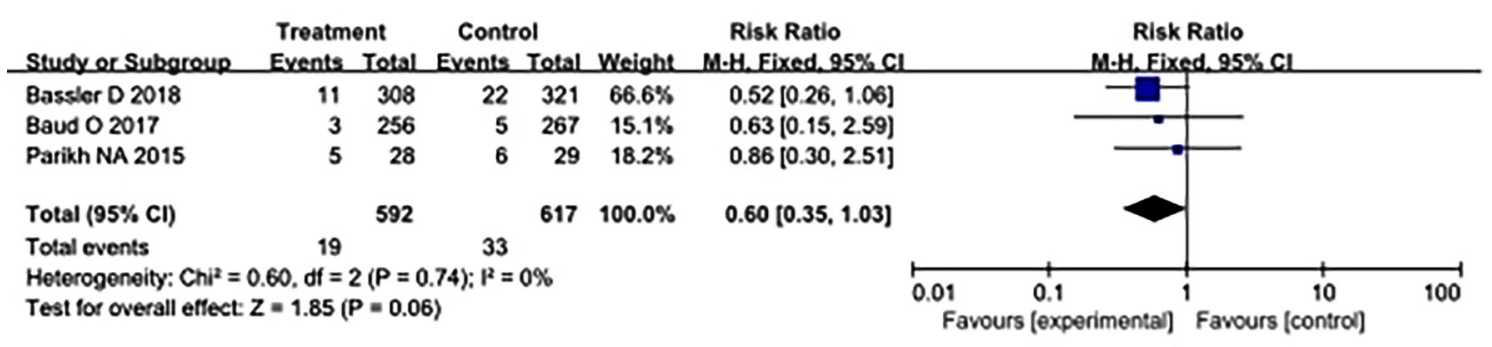

Figure 7 Hearing loss requiring amplification.

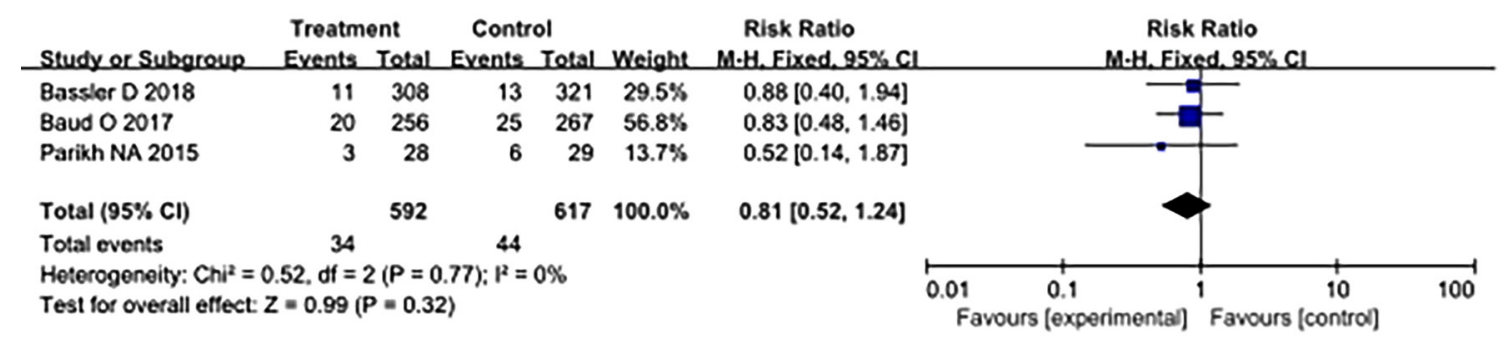

Figure 8 Bilateral blindness in the two groups.

group $(\mathrm{RR}=0.75,95 \% \mathrm{CI}: 0.46-1.21, \mathrm{P}=0.24)$.

\section{Meta-analysis results of hearing loss requiring amplification}

Figure 7 shows the forest plot of the meta-analysis results of hearing loss requiring amplification in the two groups. The figure shows that of the nine articles, there were three articles which reported on hearing loss, including a total of 1,209 very low birth weight premature babies. The treatment group included 592 patients, and the control group included 617 patients. Heterogeneity analysis of hearing loss requiring amplification was conducted, and the heterogeneity among literature was low $(\mathrm{P}=0.74$, $\left.\mathrm{I}^{2}=0 \%<50 \%\right)$. The meta-analysis results showed that hearing loss requiring amplification was not significantly different between the treatment group and the control group (RR $=0.60,95 \%$ CI: $0.35-1.03, \mathrm{P}=0.06$ ).

\section{Meta-analysis of bilateral blindness}

Figure 8 shows the forest plot of the meta-analysis results of bilateral blindness in the two groups of patients. According to the figure, among the nine studies, three reported bilateral blindness, including a total of 1,209 very low birth weight premature infants. There were 592 patients in the treatment group and 617 patients in the control group. Heterogeneity analysis of bilateral blindness was conducted, and the heterogeneity among literature was low $(\mathrm{P}=0.77$, $\left.\mathrm{I}^{2}=0 \%<50 \%\right)$. The meta-analysis results showed that there was no significant difference in bilateral blindness between the treatment group and the control group $(\mathrm{RR}=0.81,95 \%$ CI: $0.52-1.24, \mathrm{P}=0.32$ ).

\section{Meta-analysis results of severe IVH}

Figure 9 shows the forest plot of the meta-analysis results of severe IVH in the two groups of patients. It can be seen from the figure that three out of the nine studies reported on severe IVH, including a total of 399 very low birth weight premature infants. There were 201 patients in the treatment group and 198 patients in the control group. Heterogeneity analysis of severe IVH showed that the heterogeneity among literature was low $(\mathrm{P}=0.91$, $\left.\mathrm{I}^{2}=0 \%<50\right)$. The meta-analysis results showed that there was no significant difference in severe IVH between the treatment group and the control group ( $\mathrm{RR}=0.71,95 \% \mathrm{CI}$ : $0.33-1.50, \mathrm{P}=0.37)$.

\section{Meta-analysis of cystic periventricular leukomalacia}

Figure 10 shows the forest plot of the meta-analysis results 


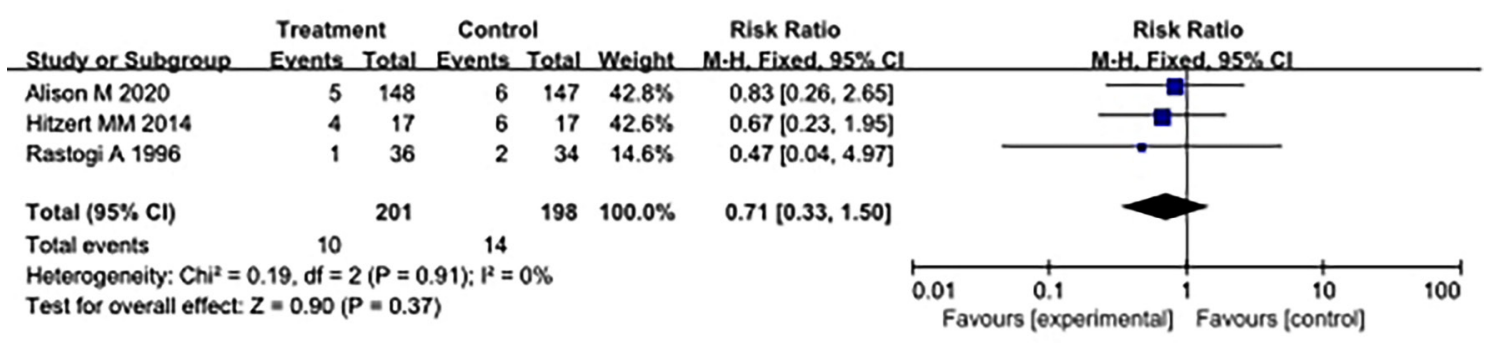

Figure 9 Severe intraventricular hemorrhage in the two groups.

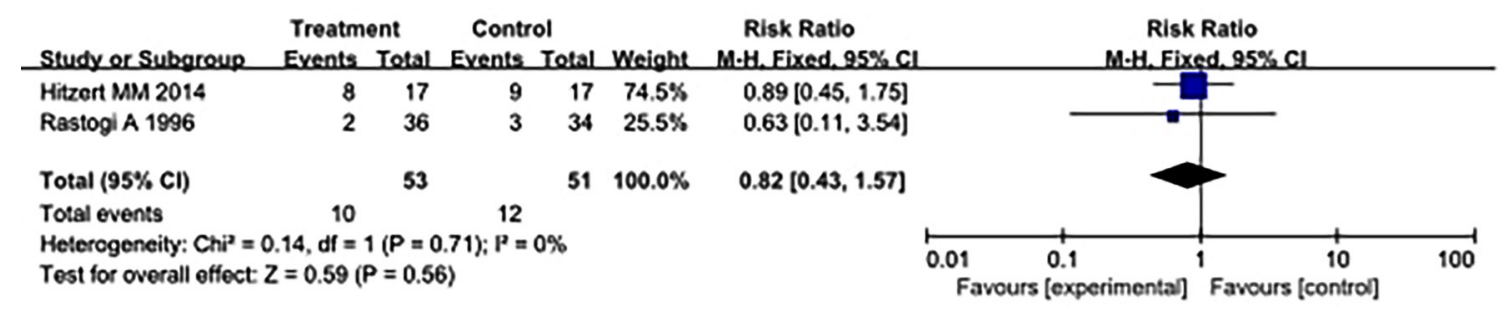

Figure 10 Cystic periventricular leukomalacia in the two groups.

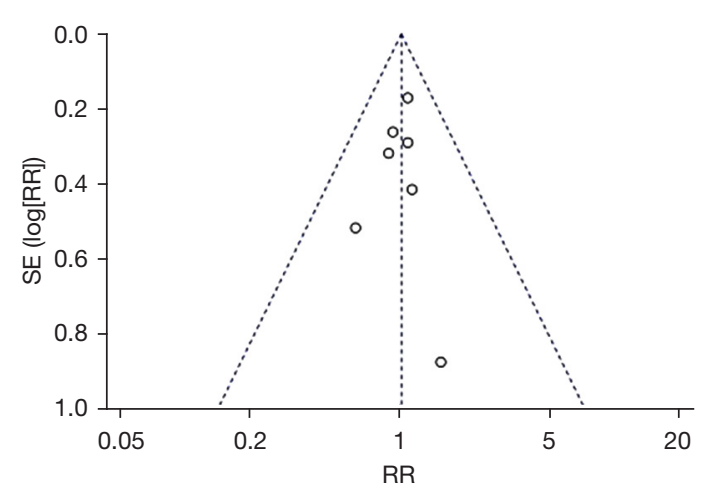

Figure 11 Funnel plot of publication bias.

of periventricular leukomalacia in the two groups of patients. According to the figure, among the nine studies, two studies reported on patients with periventricular leukomalacia. A total of 104 patients were included, including 53 very low birth weight preterm infants in the treatment group and 51 very low birth weight preterm infants in the control group. As for the heterogeneity analysis of periventricular cystic leukomalacia, the heterogeneity among literature was low $(\mathrm{P}=0.71$, $\left.\mathrm{I}^{2}=0 \%<50 \%\right)$. The meta-analysis results showed that there was no significant difference in periventricular cystic leukomalacia in the treatment group compared with the control group ( $\mathrm{RR}=0.82,95 \% \mathrm{CI}: 0.43-1.57, \mathrm{P}=0.56$ ).

\section{Publication bias results}

Figure 11 shows the funnel plot of publication bias of the included literature. Meta-analysis was conducted on the indicators of cerebral palsy in the two groups, and the funnel plot showed that the circles and the midline of some studies were basically symmetrical, and there was no bias in the publications, so the conclusions were relatively credible.

\section{Discussion}

At present, due to the improvement of the professional level of neonatal care, many premature infants with very low birth weight are born, which often results in bronchopulmonary dysplasia. However, there is no consistent conclusion on whether drug treatment will affect neurodevelopment $(15,16)$. The reason why premature infants are prone to intraventricular hemorrhage is related to the brain structure and anatomical development of premature infants. The maturity of the premature infant's brain is relatively poor. There is a region in the ventricle of premature infant called germinal matrix, which is the birthplace of nerve cells and the vascular plexus is very rich. As gestational age increases, the vascular plexus of the germinal matrix becomes less abundant in near-term life and the vascular walls become thickened. However, the germinal matrix capillary network of premature infants is particularly rich, because it is the 
birthplace of nerve cells that supply cortex and brain tissue. However, the vascular wall is particularly thin, with only a single layer of epithelial cells. In addition, there is a lack of support from fibrous connective tissue around the vascular wall, which leads to any blood flow fluctuation, increased cerebral blood flow, decreased cerebral blood flow, blood pressure fluctuation, hypoxia and unstable internal environment in premature infants. All these may lead to the rupture of these thin vascular walls and trigger intraventricular hemorrhage. In this meta-analysis, a total of nine relevant studies were included by searching and screening, and a total of 2,453 very low birth weight infants complicated with bronchial dysplasia were treated with steroids, while placebo was used as the control.

There were 6 reports on cerebral palsy of extremely low birth weight premature infants complicated with bronchial dysplasia, and the heterogeneity among studies was low $\left(\mathrm{P}=0.81, \mathrm{I}^{2}=0 \%<50 \%\right)$. There was no significant difference in cerebral palsy between the treatment group and the control group ( $\mathrm{RR}=0.99,95 \% \mathrm{CI}: 0.75-1.29, \mathrm{P}=0.93)$. This was similar to the findings of Pascal et al. (17), who also found that there was no statistically significant difference in patients with cerebral palsy between the treatment and control groups. In terms of the neurodevelopment of very low birth weight premature infants complicated with bronchial dysplasia, the results showed that there were four articles which reported on patients with cognitive impairment, three articles reported on patients with language disorders, three articles reported on patients requiring hearing loss amplification, and three articles reported on patients with bilateral blindness. The heterogeneity of cognitive impairment $\left(\mathrm{P}=0.65, \mathrm{I}^{2}=0 \%<50 \%\right)$, language impairment $\left(\mathrm{P}=0.20, \mathrm{I}^{2}=38 \%<50 \%\right)$, hearing loss requiring amplification $\left(\mathrm{P}=0.74, \mathrm{I}^{2}=0 \%<50 \%\right)$, and bilateral blindness $\left(\mathrm{P}=0.77, \mathrm{I}^{2}=0 \%<50 \%\right)$ were all low. There was a significant difference in cognitive impairment between the treatment group and the control group $(\mathrm{RR}=0.83,95 \% \mathrm{CI}$ : $0.72-0.96, \mathrm{P}=0.01$ ), suggesting that steroid treatment of very low birth weight preterm infants with bronchial dysplasia had a certain effect on cognition (18). Language disorder (RR $=0.75$, 95\% CI: 0.46-1.21, $\mathrm{P}=0.24)$, hearing loss requiring amplification ( $\mathrm{RR}=0.60,95 \% \mathrm{CI}: 0.35-1.03, \mathrm{P}=0.06)$, bilateral blindness ( $\mathrm{RR}=0.81,95 \% \mathrm{CI}: 0.52-1.24, \mathrm{P}=0.32$ ). Al-Mouqdad et al. (19) evaluated $80 \%$ of surviving infants after a follow-up of about 1.5 years and found no significant difference in neurodevelopmental disorders between the treatment group and the control group $(\mathrm{RR}=0.9095 \% \mathrm{CI}$ : $0.0 .73-1.08, \mathrm{P}=0.077)$. The MRI analysis of very low birth weight preterm infants complicated with bronchial dysplasia showed that severe IVH was reported in three articles, severe IVH was reported in two articles with cystic periventricular leukomalacia $\left(\mathrm{P}=0.91, \mathrm{I}^{2}=0 \%<50 \%\right)$, and cystic periventricular leukomalacia $\left(\mathrm{P}=0.71, \mathrm{I}^{2}=0 \%<50 \%\right)$ had low heterogeneity. Very low birth weight preterm infants complicated with bronchial dysplasia in the treatment group had severe IVH compared with the control group ( $\mathrm{RR}=0.71,95 \%$ CI: 0.33 $1.50, \mathrm{P}=0.37$ ), as well as cystic periventricular leukomalacia $(\mathrm{RR}=0.82,95 \% \mathrm{CI}: 0.43-1.57, \mathrm{P}=0.56)$. This is similar to the results of Dickinson et al. (20). There was no significant effect on MRI images of very low birth weight preterm infants with bronchial dysplasia after steroid treatment.

In this study, the risk bias of included references was assessed using the bias risk assessment map of Rev Man 5.3 software. The results showed that among the nine randomized controlled trial, the randomized controlled trial in seven studies described the correct random allocation method, seven studies used double blind, and the data of seven studies were complete. According to the analysis of cerebral palsy in two groups of patients, the funnel plot could be drawn to show that the circles and median lines in some studies were basically symmetrical, and there was no bias in publication, so the conclusions drawn were relatively credible. This indicated that the bias of the reports was small, and the overall quality of the articles included in this study and the evidence strength were high, with good reliability.

\section{Conclusions}

In this study, nine randomized controlled trials of steroid use on neurodevelopment in preterm infants with bronchial dysplasia of extremely low body weight were included through literature retrieval, and the impact of steroid use on neurodevelopment was assessed by meta-analysis. The results showed that there was good homogeneity among the studies and the analysis results were reliable. For the patients with extremely low body weight premature infants complicated with bronchial dysplasia, the use of steroid substances had a significant effect on the cognition of patients, but no significant effect on hearing, vision and language function. However, there are still some limitations in this study. The indicators of neurodevelopment are insufficient, so the relevant data of bronchial dysplasia can be increased for analysis later. The results of the analysis were affected to some extent by the equipment and the subjective consciousness of the doctor, resulting in the differences of the obtained results. 


\section{Acknowledgments}

Funding: None.

\section{Footnote}

Reporting Checklist: The authors have completed the PRISMA reporting checklist. Available at https://dx.doi. org/10.21037/tp-21-449

Conflicts of Interest: All authors have completed the ICMJE uniform disclosure form (available at https://dx.doi. org/10.21037/tp-21-449). The authors have no conflicts of interest to declare.

Ethical Statement: The authors are accountable for all aspects of the work in ensuring that questions related to the accuracy or integrity of any part of the work are appropriately investigated and resolved.

Open Access Statement: This is an Open Access article distributed in accordance with the Creative Commons Attribution-NonCommercial-NoDerivs 4.0 International License (CC BY-NC-ND 4.0), which permits the noncommercial replication and distribution of the article with the strict proviso that no changes or edits are made and the original work is properly cited (including links to both the formal publication through the relevant DOI and the license). See: https://creativecommons.org/licenses/by-nc-nd/4.0/.

\section{References}

1. Parikh NA, Kennedy KA, Lasky RE, et al.

Neurodevelopmental Outcomes of Extremely Preterm Infants Randomized to Stress Dose Hydrocortisone. PLoS One 2015;10:e0137051.

2. Doyle LW, Davis PG, Morley CJ, et al. Outcome at 2 years of age of infants from the DART study: a multicenter, international, randomized, controlled trial of low-dose dexamethasone. Pediatrics 2007;119:716-21.

3. Baud O, Trousson C, Biran V, et al. Association Between Early Low-Dose Hydrocortisone Therapy in Extremely Preterm Neonates and Neurodevelopmental Outcomes at 2 Years of Age. JAMA 2017;317:1329-37.

4. Bassler D, Shinwell ES, Hallman M, et al. Long-Term Effects of Inhaled Budesonide for Bronchopulmonary Dysplasia. N Engl J Med 2018;378:148-57.

5. Watterberg KL, Shaffer ML, Mishefske MJ, et al. Growth and neurodevelopmental outcomes after early low-dose hydrocortisone treatment in extremely low birth weight infants. Pediatrics 2007;120:40-8.

6. Baud O, Trousson C, Biran V, et al. Two-year neurodevelopmental outcomes of extremely preterm infants treated with early hydrocortisone: treatment effect according to gestational age at birth. Arch Dis Child Fetal Neonatal Ed 2019;104:F30-5.

7. Alison M, Tilea B, Toumazi A, et al. Prophylactic hydrocortisone in extremely preterm infants and brain MRI abnormality. Arch Dis Child Fetal Neonatal Ed 2020;105:520-5.

8. Hitzert MM, Roescher AM, Bos AF. The quality of general movements after treatment with low-dose dexamethasone in preterm infants at risk of bronchopulmonary dysplasia. Neonatology 2014;106:222-8.

9. Rastogi A, Akintorin SM, Bez ML, et al. A controlled trial of dexamethasone to prevent bronchopulmonary dysplasia in surfactant-treated infants. Pediatrics 1996;98:204-10.

10. Doyle LW, Cheong JL, Ehrenkranz RA, et al. Early (<8 days) systemic postnatal corticosteroids for prevention of bronchopulmonary dysplasia in preterm infants. Cochrane Database Syst Rev 2017;10:CD001146.

11. Romero R, Conde-Agudelo A, Da Fonseca E, et al. Vaginal progesterone for preventing preterm birth and adverse perinatal outcomes in singleton gestations with a short cervix: a meta-analysis of individual patient data. Am J Obstet Gynecol 2018;218:161-80.

12. Campbell S. Prevention of spontaneous preterm birth: universal cervical length assessment and vaginal progesterone in women with a short cervix: time for action! Am J Obstet Gynecol 2018;218:151-8.

13. Kuusela P, Jacobsson B, Hagberg H, et al. Secondtrimester transvaginal ultrasound measurement of cervical length for prediction of preterm birth: a blinded prospective multicentre diagnostic accuracy study. BJOG 2021;128:195-206.

14. Sawaddisan R, Kor-Anantakul O, Pruksanusak N, et al. Uterocervical angle measurement for preterm birth prediction in singleton pregnant women with no history of preterm birth and normal cervical length: A prospective cohort study. Eur J Obstet Gynecol Reprod Biol 2020;252:30-5.

15. Conde-Agudelo A, Romero R, Da Fonseca E, et al. Vaginal progesterone is as effective as cervical cerclage to prevent preterm birth in women with a singleton gestation, previous spontaneous preterm birth, and a short cervix: updated indirect comparison meta-analysis. Am J Obstet 
Gynecol 2018;219:10-25.

16. Blackwell SC, Gyamfi-Bannerman C, Biggio JR Jr, et al. 17-OHPC to Prevent Recurrent Preterm Birth in Singleton Gestations (PROLONG Study): A Multicenter, International, Randomized Double-Blind Trial. Am J Perinatol 2020;37:127-36.

17. Pascal A, Govaert P, Oostra A, et al. Neurodevelopmental outcome in very preterm and very-low-birthweight infants born over the past decade: a meta-analytic review. Dev Med Child Neurol 2018;60:342-55.

18. He Y, Zhang Y, Gao S, et al. Hydrocortisone to treat early bronchopulmonary dysplasia in very preterm infants:

Cite this article as: Gao S, Zhang $\mathrm{X}, \mathrm{Du}$ W, Zhou X, Xi Y, Ju R. Systematic review and meta-analysis: the effect of bronchopulmonary dysplasia on neurodevelopment in very low birth weight premature infants. Transl Pediatr 2021;10(11):3023-3033. doi: 10.21037/tp-21-449 study protocol for a randomized controlled trial. Trials 2020;21:762.

19. Al-Mouqdad MM, Abdelrahim A, Abdalgader AT, et al. Risk factors for intraventricular hemorrhage in premature infants in the central region of Saudi Arabia. Int J Pediatr Adolesc Med 2021;8:76-81.

20. Dickinson A, Varcin KJ, Sahin M, et al. Early patterns of functional brain development associated with autism spectrum disorder in tuberous sclerosis complex. Autism Res 2019;12:1758-73.

(English Language Editor: B. Draper) 